\title{
SYNTHESIS OF DIAMONDLIKE CARBON FILMS WITH SUPERLOW FRICTION AND WEAR PROPERTIES*
}

A. Erdemir, O. L. Eryilmaz, and G. Fenske

\author{
Energy Technology Division \\ Argonne National Laboratory \\ 9700 S. Cass Avenue \\ Argonne, IL 60439
}

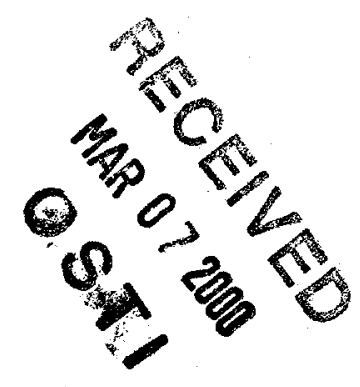

\begin{abstract}
The submitted manuscript has been created by the University of Chicago as Operator of Argonne National Laboratory under Contract No.

W-31-109-ENG-38 with the U.S. Department of Energy. The U.S.

Government retains for itself, and others acting on its behalf, a paid-up, nonexclusive, irrevocable worldwide license in said article to reproduce, prepare derivative works, distribute copies to the public, and perform publicly and display publicly, by or on behalf of the Government.
\end{abstract}

\author{
Revised, December1999
}

For presentation at 46th International Symposium, American Vacuum Society, Oct. 25-29, 1999, Washington State Convention Center, Seattle.

*Work supported by the U.S. Department of Energy, Office of Science, under Contract W-31-109-Eng-38. 


\section{DISCLAIMER}

This report was prepared as an account of work sponsored by an agency of the United States Government. Neither the United States Government nor any agency thereof, nor any of their employees, make any warranty, express or implied, or assumes any legal liability or responsibility for the accuracy, completeness, or usefulness of any information, apparatus, product, or process disclosed, or represents that its use would not infringe privately owned rights. Reference herein to any specific commercial product, process, or service by trade name, trademark, manufacturer, or otherwise does not necessarily constitute or imply its endorsement, recommendation, or favoring by the United States Government or any agency thereof. The views and opinions of authors expressed herein do not necessarily state or reflect those of the United States Government or any agency thereof. 


\section{DISCLAIMER}

Portions of this document may be illegible in electronic image products. Images are produced from the best available original document. 


\title{
SYNTHESIS OF DIAMONDLIKE CARBON FILMS WITH SUPERLOW FRICTION AND WEAR PROPERTIES
}

\author{
A. Erdemir, ${ }^{*}$ O. L. Eryilmaz, ${ }^{+}$and G. Fenske \\ Energy Technology Division \\ Argonne National Laboratory \\ 9700 S. Cass Avenue \\ Argonne, IL 60439
}

\begin{abstract}
In this study, we introduce a new diamondlike carbon (DLC) film providing a friction coefficient of 0.001 and wear rates of $10^{-9}$ to $10^{-10} \mathrm{~mm}^{3} / \mathrm{N} . \mathrm{m}$ in inert-gas environments (e.g., dry nitrogen and argon). The film was grown on steel and sapphire substrates in a plasma enhanced chemical vapor deposition system that uses using a hydrogen-rich plasma. Employing a combination of surface and structure analytical techniques, we explored the structural chemistry of the resultant DLC films and correlated these findings with the friction and wear mechanisms of the films. The results of tribological tests under a 10-N load (creating initial peak Hertz pressures of 1 and $2.2 \mathrm{GPa}$ on steel and sapphire test pairs, respectively) and at 0.2 to $0.5 \mathrm{~m} / \mathrm{s}$ sliding velocities indicated that a close correlation exists between the friction and wear coefficients of DLC films and the source gas chemistry. Specifically, films grown in source gases with higher hydrogen-to-carbon ratios had the lowest friction coefficients and the highest wear resistance. The lowest friction coefficient $(0.001)$ was achieved with a film on sapphire substrates produced in a gas discharge plasma consisting of $25 \%$ methane and $75 \%$ hydrogen.
\end{abstract}

Key Words: diamondlike carbon, superlow friction and wear, over-hydrogenation.

*To whom all correspondence should be sent.

+Permanent Address: Istanbul Technical University, Metallurgical Engineering Department, Ayazagi, Istanbul, Turkey. 


\section{INTRODUCTION}

Hard diamondlike carbon (DLC) films combine unique mechanical, chemical, optical, and electrical properties that make them very attractive for a wide range of industrial applications [1-4]. Mechanically, these films are quite hard, strong, and stiff. Chemically, they are inert and impervious to acidic and saline media. Most DLC films are electronically insulating and can be made optically transparent to visible and ultraviolet light $[1,2,4]$. Structurally, they are amorphous and made of $\mathrm{sp}^{2}$ and $\mathrm{sp}^{3}$-bonded carbon atoms. Depending on deposition process and carbon sources, they may also contain large amounts of hydrogen in their amorphous structures [5-7]. By using solid carbon or graphite targets, the deposition of hydrogen-free DLC films (i.e., $<1 \%$ hydrogen) is also feasible, especially with magnetron sputtering, arc-PVD, and laser ablation techniques $[5,6,8]$. Lately, researchers have been doping these films with a number of metallic/non-metallic species (e.g., nitrogen, fluorine, oxygen, silicon, tungsten, titanium, and niobium) to achieve better electrical and mechanical properties $[4,9,10]$.

DLC films can be deposited at temperatures ranging from subzero to $400^{\circ} \mathrm{C}$ on a variety of metallic and ceramic surfaces by using one of severa plasma or ion-beam-based physical and chemical vapor deposition (PVD and CVD) methods. During DLC deposition, carbon-bearing source gases (such as methane, acetylene, etc.) are dissociated into highly energetic ions and neutrals that are essential for the initial nucleation and subsequent growth of the DLC films. With recent advances in the PVD and CVD methods, the mass production of high-quality DLC films on all kinds of substrates has become routinely available. One example is the magnetic recording media on which even-thinner hard carbon films are deposited on magnetic recording disks to achieve protection against corrosion and wear [11]. 
The mechanical and tribological properties of the DLC films differ significantly from one study to another mainly because of the large differences in their microstructures and chemistries, as well as in hydrogen content and relative ratios of the $\mathrm{sp}^{2}$ - to $\mathrm{sp}^{3}$-bonded carbon precursors. Previous researchers have demonstrated that in addition to these intrinsic differences, the specific test conditions (i.e., load, speed, temperature, environment, lubricant, vacuum, etc.) established during each tribotest may also have a strong influence on the friction and wear performance of the DLC films [10-17]. In fact, the reported friction coefficients for these films span the range from 0.01 to $>0.5$. Among the many test parameters, relative humidity seems to have the greatest effect on the friction of DLC films. In lowhumidity or inert-gas environments, values as low as 0.01 have been reported, while in high humidity air, the friction coefficients of 0.1 to 0.3 were found $[12,17-20]$. Hydrogen-free DLC films appear to work best in humid air, while hydrogenated films perform better in dry or inert gas environments [1215]. At high temperatures, most DLC films undergo permanent chemical and microstructural changes and hence their friction and wear behavior degrades and their lifetimes shorten $[14,21]$. For example, above $300^{\circ} \mathrm{C}$, hyrogenated DLC films begin to graphitize and wear out quickly [21]. Use of certain dopants (i.e., silicon, titanium, tungsten, boron) may retard the graphitization process and hence improve the durability of DLC films at elevated temperatures.

In this study, we introduce a new diamondlike carbon film providing a friction coefficient of 0.001 to 0.003 and wear rates of $10^{-9}$ to $10^{-10} \mathrm{~mm}^{3} \mathrm{~N}$.m in inert-gas environments (e.g., dry nitrogen or argon). Specifically, we describe a new deposition procedure that can lead to the formation of a DLC film with superlow friction and wear coefficients in dry nitrogen. By using a combination of tribological and structural characterization techniques, we test and analyze these films to gain a better understanding of their structural and tribological properties. On the basis of our analytical and experimental findings, 
we propose a mechanism that elucidate the superlow friction and wear behavior of these films.

\section{EXPERIMENTAL PROCEDURES}

The DLC films used in this study were $\approx 1 \mu \mathrm{m}$ thick and deposited by a plasma enhaced CVD on the polished surfaces of AISI M50 balls (9.5 mm in diameter) and H13 steel disks, as well as on sapphire balls (6.35 mm in diameter) and sapphire disks. The films were derived from pure methane $\left(\mathrm{CH}_{4}\right)$ and mixed gas of $\mathrm{CH}_{4}$ with increasing amounts of hydrogen $\left(\mathrm{H}_{2}\right)$ in the gas discharge plasmas at room temperature. The procedure for forming DLC films on steel substrates involved first sputter-cleaning of the substrates in an Ar plasma for $30 \mathrm{~min}$ by applying a 1200-1700V bias. The substrates were then coated with a 50-70 nm-thick silicon bond layer by switching to a sputtering mode and sputtering $\mathrm{Si}$ from a target. Finally, $\mathrm{CH}_{4}$ and/or $\mathrm{CH}_{4}+\mathrm{H}_{2}$ source gases were bled into the chamber and the deposition of DLC on substrates was started. Gas pressure during deposition ranged from 10 to 13 mtorr, and the RF bias was maintained at $1600 \mathrm{~V}$. Further details of the deposition process can be found in Refs. 22 and 23 .

The friction and wear testing of the DLC coated ball and disk samples was carried out in a ball-on-disk tribometer in a dry nitrogen environment under a 10-N load (creating initial peak Hertz pressures of 1 and $2.2 \mathrm{GPa}$ on steel-steel and sapphire-sapphire test pairs, respectively) and at velocities of 0.3 to $0.5 \mathrm{~m} / \mathrm{s}$ for a distance of $5 \mathrm{~km}$. To measure the true friction coefficient of the DLC film itself, coated steel and sapphire balls were rubbed against the coated H13 steel and sapphire disks, respectively. The Vickers hardness of the steel balls and substrates was $\approx 8 \mathrm{GPa}$ and their surface roughnesses were better than $0.05 \mu \mathrm{m}$ centerline average (CLA). The surfaces of the sapphire balls and disks were polished to 
a mirror finish and their typical hardness was $\approx 35 \mathrm{GPa}$. Each test pair was tested twice in dry nitrogen ( $0 \%$ humidity) and the average friction and wear values are reported in appropriate charts. A few tests were run with uncoated test pairs to provide some baseline friction and wear data. The test chamber was purged with dry nitrogen for at least $2 \mathrm{~h}$ after $0 \%$ humidity was shown on a hygrometer display unit. Wear volume $\left(\mathrm{W}_{\mathrm{b}}\right)$ of the steel balls was determined with an optical microscope. Specifically, wear scar diameter and the ball diameter were used in the equation: $\mathrm{W}_{\mathrm{b}}=3.14 \mathrm{~d}^{4} / 64 \mathrm{r}$, where $\mathrm{r}$ is the ball radius, $d$ is the diameter of the wear scar, and $W_{b}$ is the wear volume. To simplify the calculations, we assumed that the wear scar was flat.

\section{RESULTS}

The Raman spectra of films derived from various source gases revealed broad peaks centered at $\approx 1560$ $\mathrm{cm}^{-1}$ and shouldered peaks at $\approx 1350 \mathrm{~cm}^{-1}$. The shouldered peaks were somewhat less pronounced in spectra obtained by an HeNe laser than in spectra obtained by a UV light source. In general, the films produced in this study displayed Raman features typical of DLC films and were consistent with the Raman spectra presented elsewhere $[24,25]$. SEM and TEM photomicrographs in Figure 1 show the structural morphology of a film derived from $25 \% \mathrm{CH}_{4}$ and $75 \% \mathrm{H}_{2}$. As is obvious, this film is structurally amorphous, free of volume defects, and well-bonded to the substrate.

Figure 2 shows the friction coefficients of DLC films derived from pure $\mathrm{CH}_{4}$ and $\mathrm{CH}_{4}+\mathrm{H}_{2}$ gases. The friction coefficient $(0.015)$ of the films grown in pure $\mathrm{CH}_{4}$ is clearly the highest and the friction trace of this film is somewhat unsteady. Also, it took a very long time for this film to reach the 0.015 steadstate friction coefficient. However, the friction coefficients of other DLC films grown in $\mathrm{CH}_{4}+\mathrm{H}_{2}$ are much lower at steady states. . As can be seen, the lowest friction coefficient, 0.003 , was provided by 
a film produced in a plasma consisting of $25 \% \mathrm{CH}_{4}$ and $75 \% \mathrm{H}_{2}$. When tested under the same sliding conditions, the friction coefficient of an uncoated M50 ball against the uncoated $\mathrm{H} 13$ steel disk was $\approx 0.8$.

The wear rates of DLC-coated M50 balls during sliding against DLC-coated H13 disks in dry nitrogen are summarized in Fig. 3. Except for the film grown in $50 \% \mathrm{CH}_{4}$ and $50 \% \mathrm{H}_{2}$, they follow a similar trend to that of the friction results in Fig. 2. Specifically, wear data show that balls with a $\mathrm{CH}_{4}$-grown film suffer the most wear (i.e., $9 \times 10^{-9} \mathrm{~mm}^{3} / \mathrm{N} . \mathrm{m}$ ), whereas balls with $\mathrm{CH}_{4}+\mathrm{H}_{2}$ - grown films suffer increasingly less wear. The lowest wear rate, $4.6 \times 10^{-10} \mathrm{~mm}^{3} / \mathrm{Nm}$, was afforded by the films grown in a plasma consisting of $25 \% \mathrm{CH}_{4}$ and $75 \% \mathrm{H}_{2}$ gases. Wear rate of an uncoated $\mathrm{M} 50$ ball against the uncoated $\mathrm{H} 13$ disk under the same test condition was $5 \times 10^{-6} \mathrm{~mm}^{3} / \mathrm{N} . \mathrm{m}$. Wear rates of DLC films on the disk sides were difficult to measure. As can be seen from Fig. 4, they were barely visible (Fig. 4a) and could not be detected by a contact-stylus-type profilometer at vertical magnifications as high as 40,000X (Fig. 4b). However, small wear scars were present on the rubbing contact spots of the balls, as shown in Fig. 4c. Note that the sliding contact areas of both the ball and disk are very smooth and free of any kind of visible third body layer or transfer film formation.

The results in Figs. 2 and 3 reveal a very close relationship between source gas chemistry and the friction and wear coefficients of the DLC films produced in this study. In general, the more hydrogen in the source gas plasma, the lower the friction and wear coefficients. The lowest friction and wear coefficients were afforded by a film grown in $25 \% \mathrm{CH}_{4}+75 \% \mathrm{H}_{2}$ plasma. To further substantiate this finding and to determine the effect of substrate material on friction and wear, we deposited the samequality DLC films on sapphire balls and disks in a $25 \% \mathrm{CH}_{4}+75 \% \mathrm{H}_{2}$ plasma. Friction and wear tests were run under the same conditions as those for the steel test pairs. Figure 5 shows the variation of 
friction coefficient of the sapphire test pairs with time. It is clear that the steady-state friction coefficient of this pair is $\approx 0.001$, thus verifying that this DLC film is indeed very slick and that the substrate material can influence frictional performance. Apparently, the harder and more rigid substrates (such as sapphire) provide better mechanical support and hence frictional performance than do the less-rigid steel substrates. The steady-state friction coefficient of an uncoated sapphire ball against and uncoated sapphire disk under the same test condition was $\approx 0.9$. The wear rate of a DLCcoated sapphire ball during sliding against the DLC-coated sapphire disk was $3 \times 10^{-10} \mathrm{~mm} / \mathrm{N} \cdot \mathrm{m}$ while that of the uncoated ball against the uncoated disk was $8 \times 10^{-8} \mathrm{~mm}^{3} / \mathrm{Nm}$ in dry nitrogen.

\section{DISCUSSION}

As mentioned in the Introduction section of this paper, DLC films are known for their impressive friction and wear properties but depending on their microstructure and chemistry (as well as on test and deposition parameters), the friction coefficients of these films may vary substantially (e.g., from 0.01 to 0.5 ). The results of our study further demonstrate that DLC films are indeed very slick and that their friction coefficients may vary a great deal depending on substrate material and deposition conditions or source gases. Specifically, films grown in pure $\mathrm{CH}_{4}$ plasmas exhibit relatively poor friction and wear performance, whereas the films grown in $\mathrm{CH}_{4}+$ increasing amounts of $\mathrm{H}_{2}$ plasmas exhibit increasingly better friction and wear performance. When deposited on a hard and highly rigid sapphire substrate, the DLC films of a highly hydrogenated plasma (i.e., gas content $25 \% \mathrm{CH}_{4}$ and $75 \% \mathrm{H}_{2}$ ) provide a friction coefficient of $\approx 0.001$. When compared to the friction coefficients of uncoated steel or sapphire test pairs, as well as of DLC films of other kinds, this low value may have been the lowest yet observed on any kind of solid materials, including such solid lubricants as $\mathrm{MoS}_{2}$, graphite, or diamond. 
In the past, several mechanisms were proposed to explain the low-friction nature of carbon-based materials in general, and of DLC and diamond films in particular. It has been speculated that the low friction is in general due to the highly passive nature of their sliding surfaces causing very little adhesion across their sliding interfaces. Micrographitization and formation of transfer layers $[16,21,26$ 29] on mating surfaces have also been proposed to explain the low-friction nature of these films.

From a tribological standpoint, one can argue that the extent of friction between two sliding surfaces is largely governed by the physical and chemical interactions between these surfaces. The chemistry or composition of surrounding environments also plays important roles in the friction and wear behavior of diamond and DLC films. Rougher surfaces can cause greater mechanical interlocking and hence high friction. Reduction or elimination of physical roughness can result in low friction, as demonstrated for diamond films by a number of previous researchers $[30,31]$. When the contribution of surface roughness to friction is reduced or eliminated, the extent of adhesive interactions becomes the most dominant cause of friction between two sliding surfaces. The strength of adhesive bonding across the sliding interfaces may result from a large variety of short- and long-range interactions. Some of these are very strong in nature (i.e., covalent, ionic, metallic, etc.) while others are rather weak (such as van der Waals forces, electrostatic attractions, capillary forces, etc.). High friction (i.e., 0.8) of uncoated M50 steel against uncoated H13 steel mentioned in the Results section may have been largely due to the formation of strong metallic bonds across their sliding interface (i.e., 0.9), while that of an uncoated sapphire ball against an uncoated sapphire disk may have been due to both the covalent and ionic bonds. In short, the making and breaking of bonds at the sliding interfaces largely determine the extent of friction. 
In diamond and DLC films, covalent or $\sigma$-bonds cause the strongest interactions (if available) across the sliding interface and hence give rise to high friction. For example, when diamond and hydrogenfree DLC films are friction-tested in ultrahigh vacuum or at high temperatures, they may exhibit friction coefficients of $>1$, presumably because the $\sigma$-bonds of surface carbon atoms are exposed and are free to form strong covalent bonding across the sliding interfaces [32]. If moisture or other active gaseous species such as, oxygen, hydrogen, fluorine, etc., are introduced into the vacuum chamber, the friction coefficient of diamond and of hydrogen-free DLC drops precipitously to as low as 0.05 , presumably due to the passivation of the $\sigma$-bonds and thus the elimination of strong covalent interactions across the sliding interface. This is the most widely accepted explanation for the lowfriction mechanism of diamonds [33-35].

The other important bonds for the friction and wear behavior of diamond and DLC films are the relatively weak van der Waals attraction and $\pi$-bonding, which are more relevant to graphite than to diamond or high-quality DLCs. When the sliding surfaces of diamond or DLC are graphitized under the influence of high thermal or mechanical loadings at high sliding velocities, the extent of van der Vaals and $\pi$-bonds may also become very important and dominate the frictional performance of these materials [26-29]. Furthermore, certain DLC films may contain high proportions of $\mathrm{sp}^{2}$-bonded or graphitic carbon precursors in their structures, hence the residual $\pi$-bonding can also play a major role on the friction and wear performance of these films. Lastly, in humid air, several mono layers of water molecules and/or other gaseous species may have been present on the surfaces of sliding diamond and DLC films. These adsorbed layers may form a meniscus in and around the contact spots that can in turn create capillary forces. In vacuum or well-controlled inert-gas environments, such forces are greatly 
reduced or essentially absent, but other residual gaseous species such as oxygen, hydrogen, etc., may chemisorb on these surfaces and dominate the friction and wear behavior of diamond and DLC.

In this study, the most striking observation we made was the existence of a close relationship between the source gas chemistry and the friction and wear performance of the resultant DLC films. Specifically, the DLC films produced in source gases with increasing amounts of hydrogen exhibited lower and lower friction and wear coefficients (see Figs. 2 and 3), with the lowest friction coefficient, 0.003 provided by a DLC film grown in a $25 \% \mathrm{CH}_{4}+75 \% \mathrm{H}_{2}$ plasma. The films grown in a pure $\mathrm{CH}_{4}$ plasma provided the highest friction coefficient of 0.015 . These observations suggests that hydrogen plays a critical role in the friction and wear mechanism of DLC films. For the superlow friciton coefficients of DLC films produced in our study, we propose the mechanistic explanation given in the next paragraph..

As discussed earlier, hydrogen can chemically bond to and effectively passivate the free $\sigma$-bonds of carbon atoms in diamond and related materials and make these materials chemically very inert [35-37]. Note that the $\mathrm{C}-\mathrm{H}$ bonding is covalent and extremely strong (stronger than single $\mathrm{C}-\mathrm{C}, \mathrm{C}-\mathrm{O}$, or $\mathrm{C}-\mathrm{N}$ bonds). We believe that when extra $\mathrm{H}_{2}$ is used during DLC deposition, several important events occur and determine the structural chemistry of the DLC films that govern friction and wear behavior. First, it is logical to claim that the amount of hydrogen in the bulk, as well as on the surface, of the DLC films will increase when extra hydrogen is used in the gas discharge plasmas. Most of the hydrogen atoms are expected to be paired with the $\sigma$-bonds of carbon atoms, but some unbonded free hydrogen may also be present as interstitial species in the structure. Increased hydrogen density in the bulk and on the surface should effectively diminish or even eliminate the possibility of any unoccupied $\sigma$-bonds remaining and participating in adhesive interactions during sliding. Second, hydrogen is known to 
effectively etch out or remove the $\mathrm{sp}^{2}$-bonded or graphitic carbon precursor from the film surface and thus prevent the formation of planar graphitic phases and/or cross-linking that can give rise to $\pi$ bonding [38]. When DLC films are prepared in a highly hydrogenated plasma and under energetic hydrogen ion bombardment, strong $\mathrm{C}-\mathrm{H}$ bonding rather than $\mathrm{C}=\mathrm{C}$ double bonding should be favored. As explained above, the existence of residual $\pi$-bonding that can result from $\mathrm{C}=\mathrm{C}$ double bonds in DLC can give rise to high friction. Finally, we believe that perhaps some of the carbon atoms (at least those on the surface) were dihydrated, that is to say, two hydrogen atoms were bonded to each carbon atom on the surface. This can occur on the unreconstructed (100) surfaces of diamond structures under some special or super-critical conditions [38] that may have been created by the energetic hydrogen bombardment in a highly hydrogenated discharge plasma. The existence of dihydrated carbon atoms on the surfaces will increase hydrogen density of these surfaces and provide better shielding or passivation and thus superlow friction.

As mentioned above, other forces such as van der Waals and capillary forces, as well as electrostatic attraction can also be present and cause adhesion and hence friction at the sliding interfaces of DLC films. Because we ran the friction tests in a clean, dry nitrogen environment, the extent of capillary forces due to moisture precipitation on the sliding surfaces should be minimal or essentially absent. As for the van der Waals forces, they will be present at the sliding interfaces but their relative contributions to overall frictional force should be insignificant because we used very high contact loads in our tests. As for the possibility of electrostatic attraction, we feel that since the DLC films are in general dielectric, their sliding surfaces can certainly accumulate static electrical charges. The main question is whether these charges will cause attraction or repulsion. When the free electrons of hydrogen atoms pair with the dangling $\sigma$-bonds of carbon atoms, the electrical charge density is permanently shifted 
to the other side of the nucleus of the hydrogen atom and away from the surface. Such a shift in charge density allows the positively charged hydrogen proton in its nucleus to be closer to the surface than the electron which is used up by the $\sigma$-bond of the surface carbon atoms. We believe that the creation of such a dipole configuration at the sliding interface should give rise to electrostatic repulsion rather than attraction between the hydrogen-terminated sliding surfaces of the DLC films.

In short, we believe that hydrogen plays a key role in both the type and extent of chemical/physical interactions and hence the friction ofDLC films. Films grown in hydrogen-rich plasmas are more likely to contain more hydrogen on their sliding surfaces, in their microstructures than will the films grown in pure $\mathrm{CH}_{4}$ so that these films are chemically more inert and their covalent $\sigma$-bonds (which can cause high adhesion/friction) are absent.

\section{CONCLUSIONS}

The friction and wear results presented in this study demonstrate that a significant difference exists in the tribological properties of DLC films derived from pure $\mathrm{CH}_{4}$ and hydrogen-rich $\mathrm{CH}_{4}$ source gas plasmas. The $\mathrm{CH}_{4}$-grown DLC films exhibited the highest friction coefficients and wear rates, while the $25 \% \mathrm{CH}_{4}+75 \% \mathrm{H}_{2}$-grown films provided the lowest friction and wear. The performance of other films fell between those of these two. We propose that these differences are mainly due to the difference in hydrogen concentration on the sliding surfaces as well as within the bulk DLC structures. Higher hydrogen concentration on sliding surfaces, is analogous to better shielding or passivation of carbon bonds and hence lower friction. 


\section{ACKNOWLEDGMENTS}

This work was supported by the U.S. Department of Energy, Office of Science, under Contract W-31-109-Eng-38. The authors would like to thank R. Csencsits of Argonne for TEM microscopy and $M$. Beschliesser for help in wear analyses.

\section{REFERENCES}

1. J. F. Braza and T. S. Sudarshan, Mat. Sci. and Technol., 8(1992)574.

2. A. Matthews and S. S. Eskildsen, Diamond and Rel. Mat. 3(1994)902.

3. S. Neuville and A. Matthews, MRS Bull., 22(9)(997) 22.

4. C. Donnet, Surf. Coat. Technol. 100/101(1998)180.

5. H. Ronkainen, J. Koskinen, J. Likonen, S. Varjus, and J. Vihersalo, Diamond and Rel. Mater. $3(1993) 1329$.

6. J. J. Cuomo, J. P. Doyle, J. Bruley, and J. C. Liu, Appl. Phys. Lett., 58(1991)1.

7. R. Wei, P. J. Wilbur, A. Erdemir, and F. M. Kustas, Surf. Coat. Technol., 51(1992)139

8. A. A. Voevodin, M. S. Donley, and J. S. Zabinski, Surf. Coat. Technol., 92(1997)42.

9. H. Dimgen and C. P. Klages, Surf. Coat. Technol., 49(1991)543.

10. S. J. Harris, A. M. Weiner, and W.-J. Meng, Wear, 211(1997)208.

11. B. Bhushan, Diamond Rel. Mat., 8(1999)1985.

12. A. Erdemir, M. Switala, R. Wei, and P. Wilbur, Surf. Coat. Technol., 50(1991)17.

13. C. Donnet and A. Grill, Surf. Coat. Technol., 94-95(1997)456.

14. A. Grill, V. Patel, and B. Meyerson, Surf. Coat. Technol., 49(1991)530.

15. J. Koskinen, D. Schneider, H. Ronkainen, T. Muukkonen, S. Varjus, P. Burck, K. Holmberg, and H.-J. Scheibe, Surf. Coat. Technol., 08-109(1998)385.

16. A. Erdemir, C. Bindal, G. R. Fenske, and P. Wilbur, Tribol. Trans., 39(1996)735.

17. C. Donnet, M. Belin, J. C. Martin, J. M. Martin, A. Grill, and V. Patel, Surf. Coat. Technol., 6869(1994)626.

18. C. Donnet, T. Le Mogne, L. Ponsonnet, M. Belin, A. Grill, and V. Patel, Tribology Letters, 4 (1998) $259-265$.

19. D. S. Kim, T. E. Fischer, and B. Gallois, Surf. Coat. Technol, 49(1991)537. 
20. K. Holmberg, J. Koskinen, H. Ronkainen, J. Vihersalo, J. P. Hirvonen, and J. Likonen, Diamond Films Technol., 4(1994)113.

21. A. Erdemir and G. R. Fenske, Tribol. Trans., 39 (1996) 787.

22. A. Erdemir, G. R. Fenske, J. Terry, and P. Wilbur, Surf. Coat. Technol., 94-95(1997)525.

23. A. Erdemir, I. B. Nilufer, O. L. Eryilmaz, M. Beschliesser, and G. Fenske, Surf. Coat. Technol., 120-121(1999)589.

24. D. S. Knight and W. B. White, J. Mater. Res., 4(1989)385.

25. M. A. Tamor and W. C. Vassell, J. Appl. Phys., 76(1994)3823.

26. Y. Liu, A. Erdemir, and E. I. Meletis, Surf. Coat. Technol., 82 (1996) 48.

27. A. Erdemir, M. Halter, G. R. Fenske, C. Zuiker, R. Csencsits, A. R. Krauss, and D. M. Gruen, Tribol. Trans., 40(1997)667.

28. A. Erdemir, C. Bindal, and C. Zuiker, Surf. Coat. Technol., 86-87(1996)692.

29. A. Erdemir, F. A. Nichols, X. Z. Pan, R. Wei, and P. Wilbur, Diamond and Rel. Mat., 3 (1993) 119.

30. I. P. Hayward, I. L. Singer, and L. E. Seitzman, Wear, 157 (1992)215.

31. A. Erdemir, M. Halter, G. R. Fenske, A. Krauss, D. M. Gruen, S. M. Pimenov, V. I. Konov, Surf. Coat. Technol., 94-96 (1997)537.

32. K. Miyoshi, R. L. C. Wu, A. Garscadden, P. N. Barnes, and H. E. Jackson, J. App. Phys., 74 (1993), 4446.

33. S. V. Pepper, J. Vac. Sci. Technol., 20 (1982) 643.

34. F. P. Bowden and J. E. Young, Proc. Roy. Soc., London, 208 (1951) 444.

35. F. P. Bowden and A. E. Hanwell, Proc. Roy. Soc., London, A295 (1966) 233.

36.M. Dugger, D. Peebles, and L. Pope, Counterface Material and Ambient Atmosphere: Role in the Tribological Performance of Diamond Films,"in Surface Science Investigations in Tribology, Experimental Approaches, (Y.-W. Chung, A. M. Homolo, and G. B. Street, Eds.), ACS Symposium Series 485, American Chemical Society, Washington D.C., (1992), pp. 72-102.

37. T. E. Derry, C. C. P. Madiba, and J. P. F. Sellschop, Nuc. Inst. \& Methods in Phys., 218 (1993)559. 38. S. J. Harris and G. D. Goodwin, J. Phys. Chem., 97(1993)23. 


\section{FIGURE CAPTIONS}

Figure 1. (a) Scanning and (b) transmission electron micrographs of DLC films produced in gas discharge plasma consisting of $25 \% \mathrm{CH}_{4}$ and $75 \% \mathrm{H}_{2}$.

Figure 2. Variation of friction coefficients of DLC films derived from pure $\mathrm{CH}_{4}$ and various $\mathrm{CH}_{4}+\mathrm{H}_{2}$ plasmas.

Figure 3. Wear rates of various DLC-coated M50 balls during sliding against DLC-coated H13 disks in dry nitrogen.

Figure 4. Physical condition of rubbing surfaces of (a) M50 steel ball and (b) H13 steel disk as viewed by SEM and (c) surface profilometry trace across same wear track in (b).

Figure 5. Friction coefficient of DLC film produced on sapphire substrates in a $25 \% \mathrm{CH}_{4}+75 \% \mathrm{H}_{2}$ plasma. 


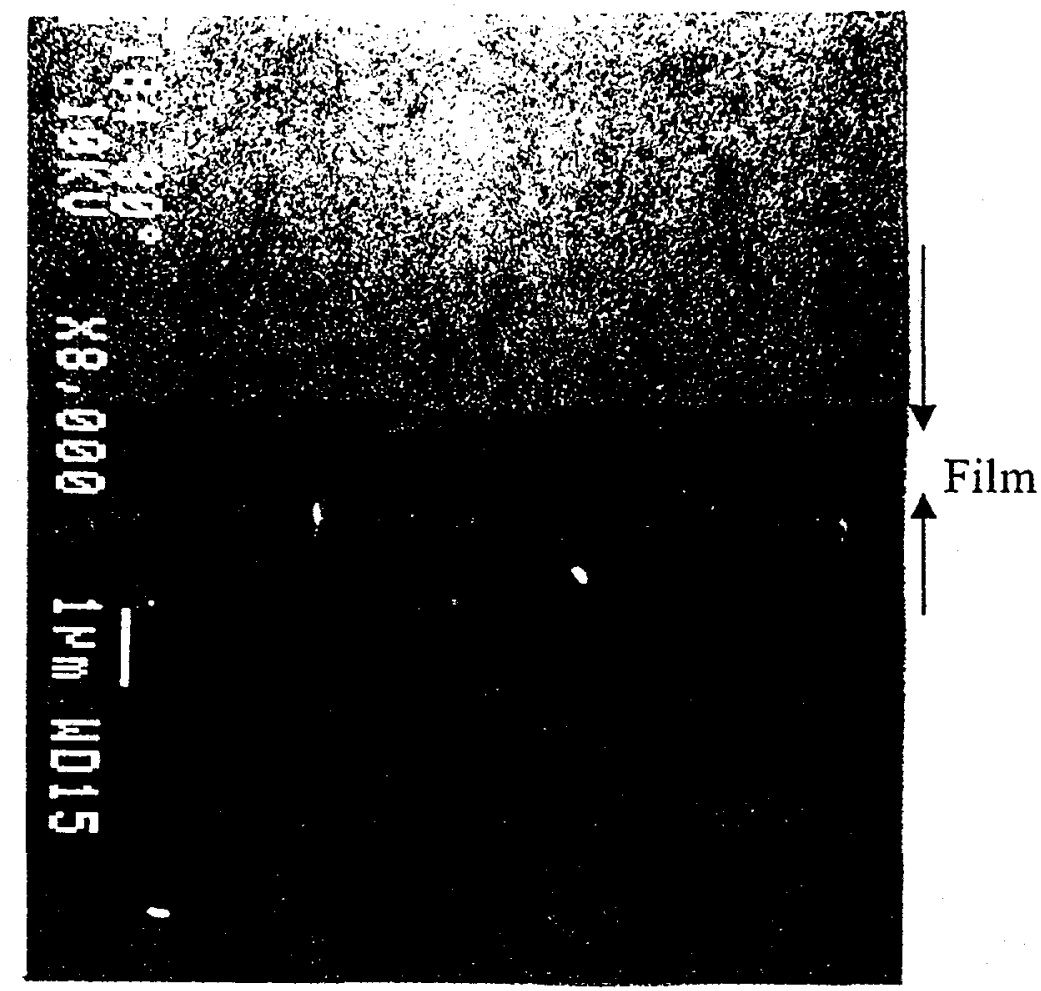

(a)

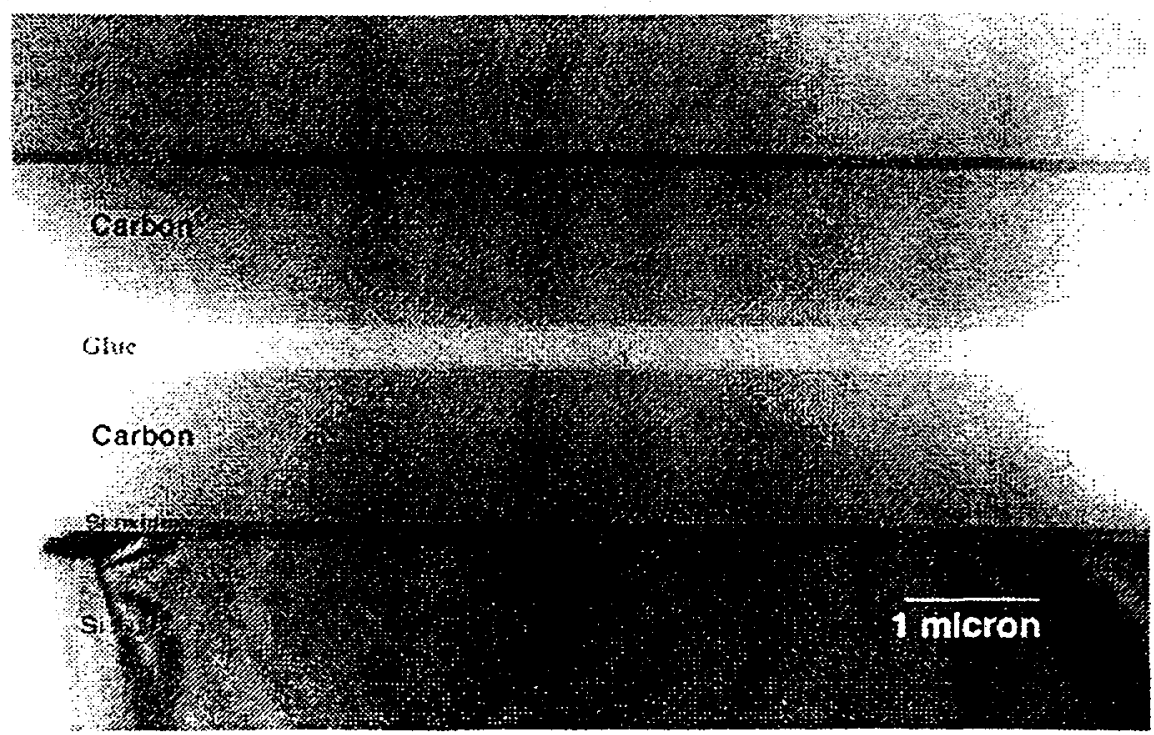

(b) 


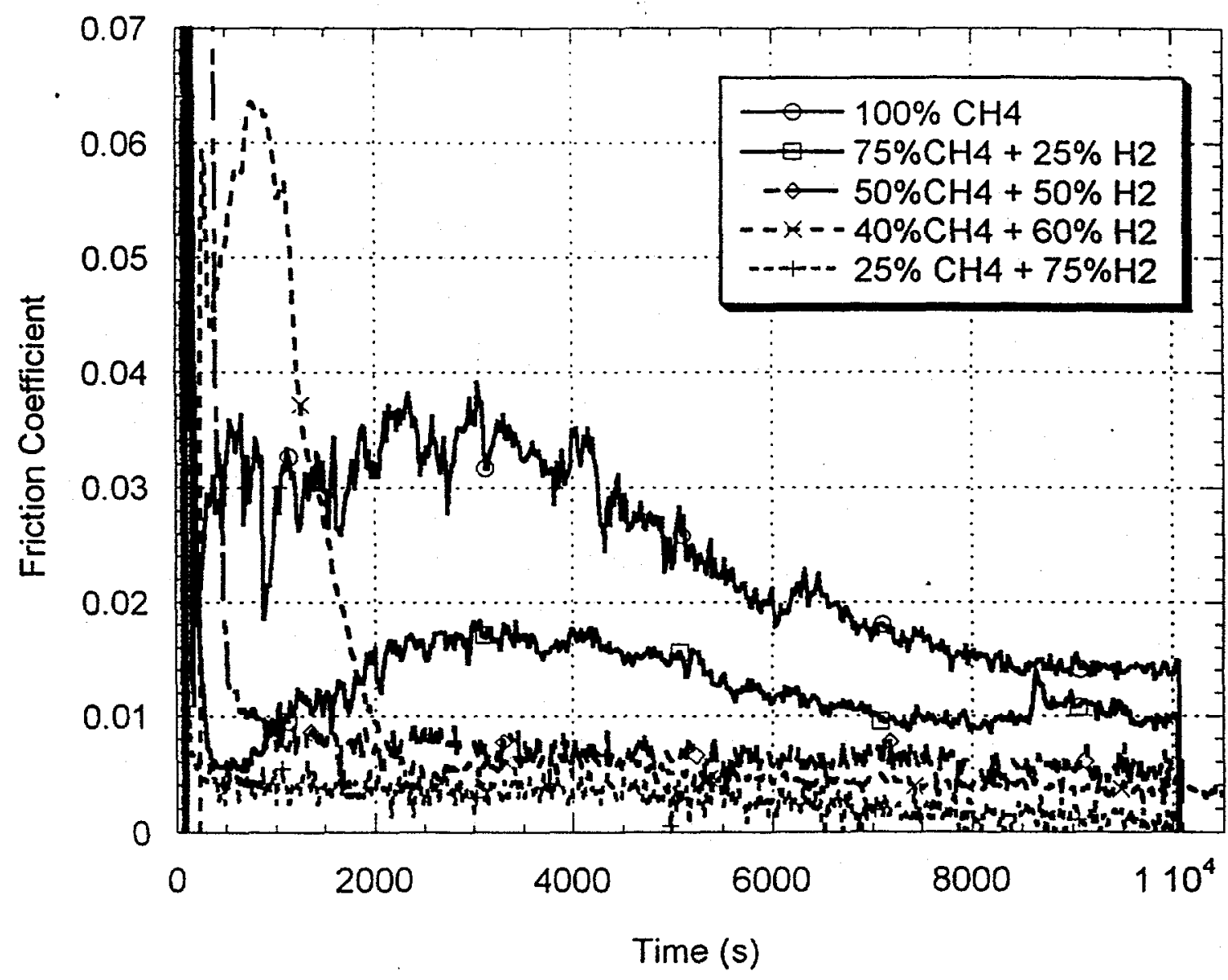

Figure 2. 


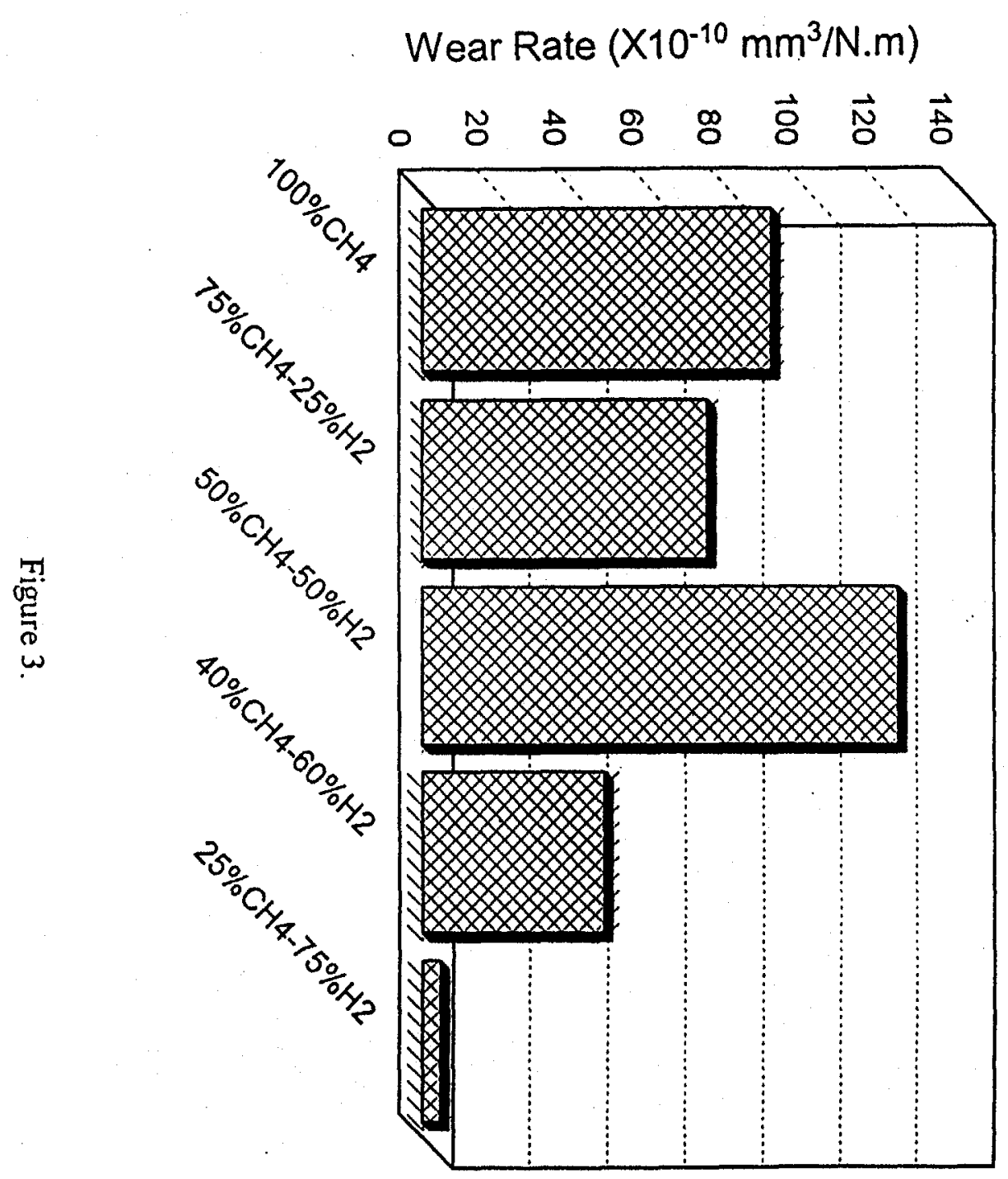




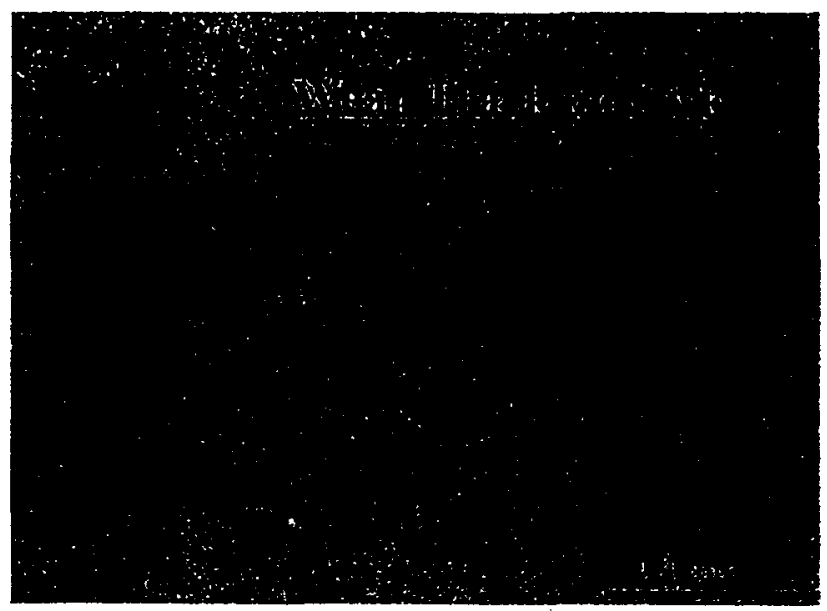

(a)

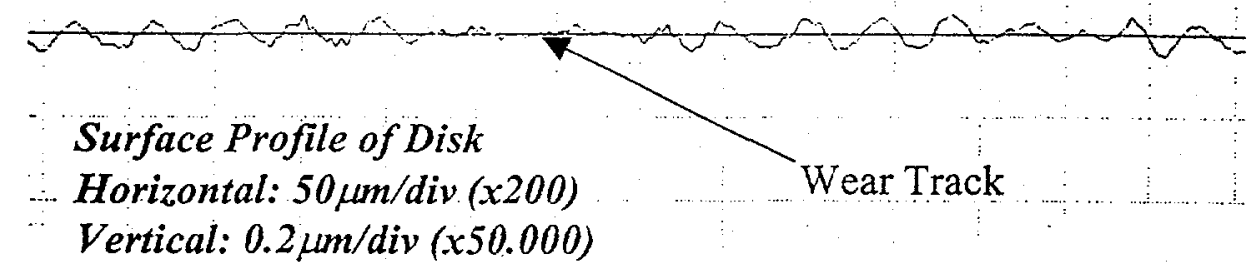

(b)

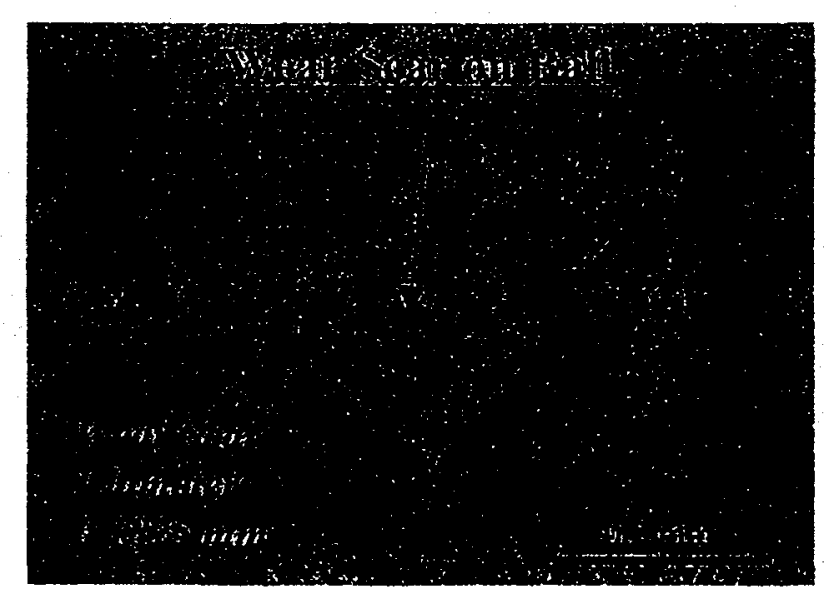

(c)

Figure 4. 


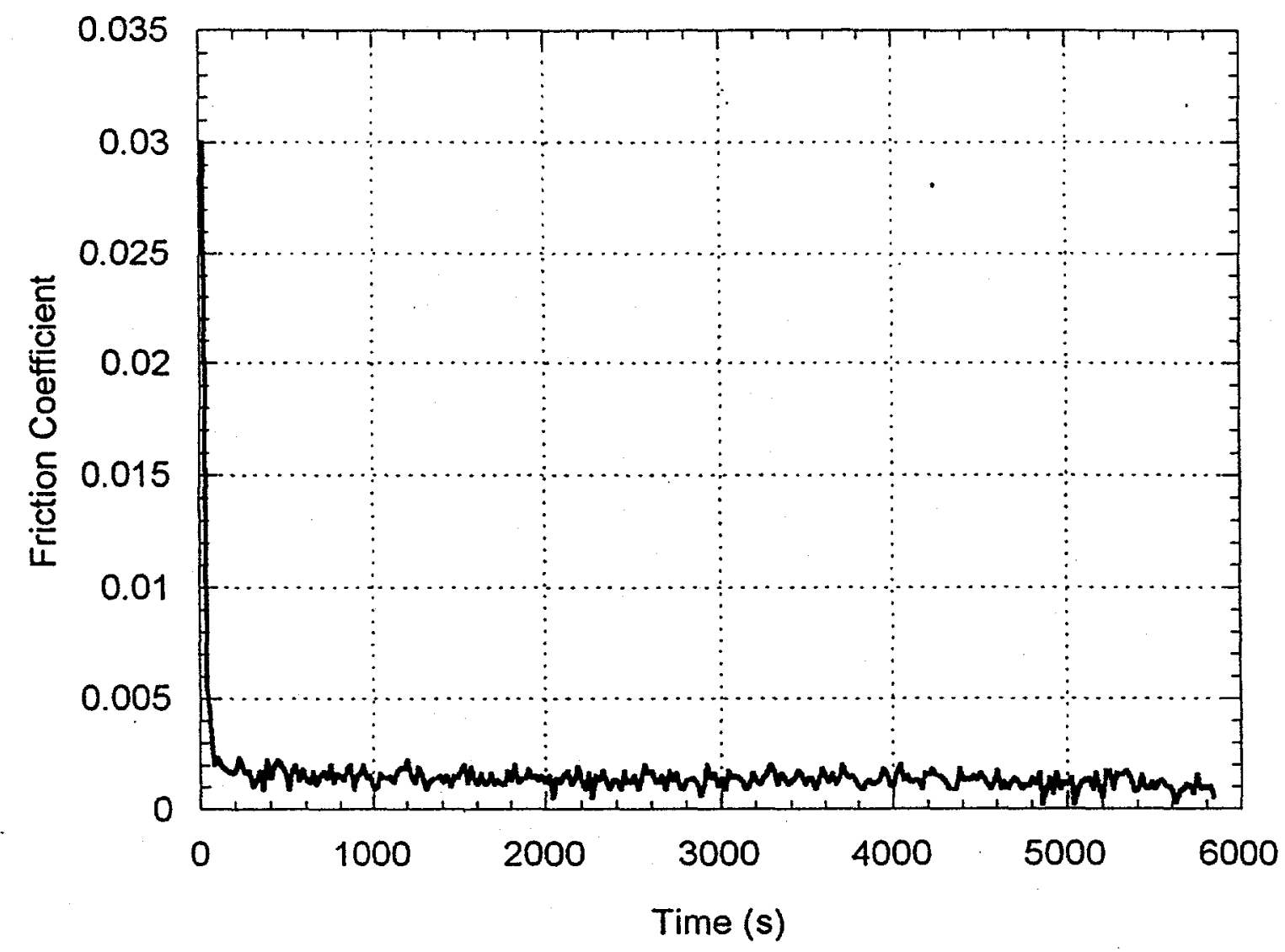

Figure 5. 